УДК 54.05

\title{
ИССЛЕДОВАНИЕ МЕТОДАМИ КР, РФА, РЭМ И АСМ СУЛЬФАТОВ АРАБИНОГАЛАКТАНА, ПОЛУЧЕННЫХ С ИСПОЛЬЗОВАНИЕМ СУЛЬФАМИНОВОЙ КИСЛОТЫ
}

\author{
(C) Б.Н. Кузнецов ${ }^{1,2 *}$, Н.Ю. Васильева ${ }^{1,2}$, А.В. Левданский ${ }^{1}$, А.А. Карачаров ${ }^{1}$ А.С. Крылов, \\ Е.В. Мазурова ${ }^{1}$, Г.Н. Бондаренко ${ }^{1}$, В.А. Левданский ${ }^{1,2}$, А.С. Казаченко ${ }^{1,2}$ \\ ${ }^{1}$ Институт химии и химической технологии СО РАН, ФИЦ КНЦ СО РАН, \\ Академгородок, 50-24, Красноярск, 660036 (Россия), e-mail: inm@icct.ru \\ ${ }^{2}$ Сибирский федеральный университет, пр. Свободный, 79, Красноярск, \\ 660041 (Россия) \\ ${ }^{3}$ Институт фризики им. КИренского СО РАН, ФИЦ КНЦ СО РАН, \\ Академгородок, 50-38, Красноярск, 660036 (Россия)
}

\begin{abstract}
Методами комбинационного рассеивания (КР), рентгенофазового анализа (РФА), растровой электронной микроскопии (РЭМ), атомно-силовой микроскопии (АСМ) изучено строение натриевых солей сульфатов арабиногалактана (АГ), полученных сульфатированием АГ древесины лиственницы смесью сульфаминовая кислота - мочевина в среде 1,4-диоксана. Введение сульфатных групп в структуру арабиногалактана подтверждено появлением в спектрах КР новых полос поглощения, относящихся к деформационным колебаниям $\delta\left(\mathrm{SO}_{3}\right)$ при $420 \mathrm{~cm}^{-1}$ и $\delta(\mathrm{O}=\mathrm{S}=\mathrm{O})$ при $588 \mathrm{~cm}^{-1}$, валентным колебаниям $v(\mathrm{C}-\mathrm{O}-\mathrm{S})$ при $822 \mathrm{~cm}^{-1}$, симметричным валентным колебаниям $v_{\mathrm{s}}(\mathrm{O}=\mathrm{S}=\mathrm{O})$ при $1076 \mathrm{~cm}^{-1}$, асимметричным валентным колебаниям $v_{\text {as }}(\mathrm{O}=\mathrm{S}=\mathrm{O})$ при $1269 \mathrm{~cm}^{-1}$. Согласно данным РФА, в процессе сульфатирования происходит аморфизация структуры арабиногалактана. Методом РЭМ установлено существенное отличие морфологии сульфатированного и исходного арабиногалактана. Исходный АГ состоит из частиц преимущественно глобулярной формы размером от 10 до 90 мкм, а сульфаты арабиногалактана - из частиц различной формы с размерами 1-8 мкм. По данным АСМ поверхность пленки сульфатированного арабиногалактана состоит из достаточно однородных сферических частиц размером около 70 нм. Величина среднеквадратичной шероховатости поверхности равна 33 нм. Поверхность пленки сульфатированного АГ не содержит посторонних примесей.

Ключевые слова: физико-химическое исследование, сульфатированный арабиногалактан, «зеленый» синтез, сульфаминовая кислота, мочевина.
\end{abstract}

Работа выполнена при финансовой поддержке РФФИ и Правительства Красноярского края в рамках научного проекта № 16-43-242083.

В работе использованы приборы Красноярского регионального центра коллективного пользования СO РAH.

\section{Введение}

Сульфатированные производные арабиногалактана (АГ) являются аналогом гепарина - вещества животного происхождения, обладающего антикоагулянтной активностью [1]. Однако гепарин может быть заражен патогенами и вирусами, что приводит к необходимости поиска его синтетических и природных

Кузнецов Борис Николаевич - заведующий лабораторией, доктор химических наук, профессор, Институт химии и химической технологии СО РАН, заведующий кафедрой, Сибирский федеральный университет, тел.: (391) 249-48-94, e-mail: bnk@icct.ru Васильева Наталья Юрьевна - старший научный сотрудник, кандидат химических наук, доцент, тел.: (391) 205-19-42, e-mail: vasilyeva.nata@mail.ru Продолжение на с. 44 аналогов. Сульфатированные производные полисахаридов проявляют высокую антикоагулянтную и гиполипидемическую активность, что делает перспективным их применение для профилактики и лечения сердечно-сосудистых заболеваний [2].

Сульфаты АГ могут быть получены с использованием различных сульфатирующих агентов: комплекса $\mathrm{SO}_{3}$ - ДМФА в среде ДМСО [3],

\footnotetext{
* Автор, с которым следует вести переписку
} 
комплекса $\mathrm{SO}_{3}$ - пиридин в среде ДМФА [4], комплекса $\mathrm{SO}_{3}$ - пиридин в среде пиридина [5]. Во всех перечисленных способах получения сульфатированных производных АГ применяются токсичные или экологически опасные сульфатирующие реагенты и растворители.

Ранее нами была установлена возможность сульфатирования арабиногалактана сульфаминовой кислотой в диоксане в присутствии основного катализатора - мочевины [6]. Это позволило разработать новый, более простой и экологически безопасный, чем известные, способ синтеза сульфатированного арабиногалактана. Сульфаты АГ, полученные новым способом, были изучены методами ИК и ${ }^{13} \mathrm{C}$ ЯМР спектроскопии [6].

В настоящей работе проведено их углубленное физико-химическое исследование методами спектроскопии комбинационного рассеяния (КР), рентгенофазового анализа (РФА), растровой электронной (РЭМ) и атомно-силовой микроскопии (АСМ).

\section{Экспериментальная часть}

В качестве исходного сырья использовали арабиногалактан (АГ) древесины лиственницы сибирской (Larix sibirica Ledeb.) производства OOО «Химия древесины» (Иркутск, Россия) под наименованием препарата «ФиброларС».

Сульфатирование АГ осуществляли по методике [6] сульфаминовой кислотой в диоксане в присутствии основного катализатора - мочевины. Затем полученную аммониевую соль сульфата АГ переводили в натриевую соль (содержание серы 13,0\% масс.). Прозрачные пленки сульфатированных образцов АГ получали испарением 6-7\% водных растворов на гладкой стеклянной подложке.

КР-спектры образцов были сняты на Bruker RFS 100/S спектрометре с охлаждаемым жидким азотом $\mathrm{Ge}$ диодом в качестве детектора. В качестве источника света для возбуждения рамановского рассеяния применялся $\mathrm{Cw}-\mathrm{Nd}$ : YAG лазер с возбуждающей линией 1,064 нм. КР-спектры были записаны в диапазоне 200-3500 $\mathrm{cm}^{-1}$, используя рабочее спектральное разрешение $2 \mathrm{~cm}^{-1}$. Анализ данных был выполнен с помощью OriginPro 7.0 (OriginLab Corporation, Массачусетс США).

Рентгенофазовый анализ (РФА) проведен на рентгеновском дифрактометре ДРОН-3 с использованием $\mathrm{Cu}$ К $\alpha$ монохроматизированного излучения $(\lambda=0,154$ нм), напряжение U 30 кB, сила тока 25 мА. Шаг сканирования 0,02 град., время накопления в точке 1 с. Съемку проводили в интервале брэгговских углов $2 \Theta$ от 5,00 до 70,00 град.

Электронные микрофотографии получены на растровом электронном микроскопе ТМ-1000 HITACHI (Япония) с ускоряющим напряжением $15 \mathrm{kV}$ и с увеличением от 100 до 10000 крат с разрешением 30 нм.

Исследования пленок сульфатированного АГ методом АСМ в полуконтактной моде проводились с использованием мультимодового сканирующего зондового микроскопа Solver P47 (НТ-МДТ, Москва). Сканирование производилось не менее чем в 3-4 точках на нескольких площадках. Скорость сканирования составляла 1,5-2,0 Гц, разрешение получаемого изображения 256×256 точек.

Левданский Александр Владимирович - научный сотрудник, кандидат химических наук, тел.: (391) 205-19-42, e-mail: alexsander.1@mail.ru Карачаров Антон Александрович - научный сотрудник, кандидат химических наук, тел.: (391) 205-19-28, e-mail: antonkaracharov@ya.ru

Крылов Александр Сергеевич - старший научный сотрудник, кандидат химических наук,

тел.: (391) 249-45-10, e-mail: shusy@iph.krasn.ru Мазурова Елена Валентиновна - научный сотрудник, кандидат технических наук, тел.: (391) 249-55-87, e-mail: kargin@icct.ru

Бондаренко Галина Николаевна - научный сотрудник, кандидат химических наук, тел.: (391) 249-47-34, e-mail: gal@ksc.krasn.ru

Левданский Владимир Александрович - главный научный сотрудник, доктор химических наук, доцент, тел.: (391) 249-55-84, e-mail: vlevdanskij@mail.ru Казаченко Александр Сергеевич - младший научный сотрудник, тел.: (391) 205-19-42,

e-mail:malenkii-krolik@mail.ru

\section{Результаты и обсуждение}

В продолжение работ по изучению сульфатов АГ, полученных сульфатированием сульфаминовой кислотой в присутствии мочевины в среде диоксана [6], выполнено исследование натриевых солей сульфатов АГ методами КР, РФА, РЭМ и АСМ.

Введение сульфатной группы в структуру АГ подтверждено появлением в КР-спектрах натриевых солей сульфатированных образцов АГ новых полос поглощения в областях 42, 588, 822, 1076, $1269 \mathrm{~cm}^{-1}$ (рис. 1).

Полоса поглощения в области $420 \mathrm{~cm}^{-1}$ coответствует деформационным колебаниям $\mathrm{SO}_{3}$ групп $\delta\left(\mathrm{SO}_{3}\right)$, а полоса при $588 \mathrm{~cm}^{-1}$ может быть отнесена к деформационным колебаниям $\delta(\mathrm{O}=\mathrm{S}=\mathrm{O})$. Полоса поглощения при $822 \mathrm{~cm}^{-1}$ при- 
суща $\mathrm{C}-\mathrm{O}-\mathrm{S}$ валентным колебаниям v(C-O-S). Характер поглощения в области 1050-1150 см ${ }^{-1}$ сульфатированного арабиногалактана значительно отличается от характера поглощения исходного АГ. В этой области в КР-спектре полисахаридов могут находиться полосы поглощения валентных колебаний гликозидных связей v(COC) и пиранозных циклов, а для сульфатированных полисахаридов и симметричные валентные колебания $v_{\mathrm{s}}(\mathrm{O}=\mathrm{S}=\mathrm{O})$ [7]. В спектре сульфатированного АГ доминирует полоса поглощения при $1076 \mathrm{~cm}^{-1}$, которая принадлежит симметричным валентным колебаниям $v_{\mathrm{s}}(\mathrm{O}=\mathrm{S}=\mathrm{O})$. Пик при $1269 \mathrm{~cm}^{-1}$ является сигналом асимметричных валентных колебаний $v_{\text {as }}(\mathrm{O}=\mathrm{S}=\mathrm{O})$.

Образцы АГ, выделенного из древесины лиственницы, имеют аморфное строение [8]. Сопоставление рентгенограмм образцов исходного АГ и АГ, сульфатированного сульфаминовой кислотой в присутствии мочевины в среде диоксана (рис. 2), показало, что в процессе сульфатирования происходит дальнейшая аморфизация структуры материала. На рентгенограмме сульфатированного образца АГ наблюдалось сглаживание пика в интервале углов от 15 до $25^{\circ} \Theta$.

Методом растровой электронной микроскопии проведено исследование образцов АГ до и после сульфатирования (рис. 3). Исходный АГ состоит из агрегированных и одиночных частиц различной формы и размера. Преобладают частицы глобулярной формы с диаметром от 10 до 90 мкм. Также присутствуют агломераты частиц, размер которых достигает 300 мкм.

После сульфатирования образцы имеют морфологию, несколько отличную от исходного АГ (рис. 3). Сульфатированный АГ состоит из различных по форме частиц с преобладающими размерами 1-8 мкм, причем некоторые частицы образуют агломераты с размерами 12-20 мкм.

Синтезированные пленки сульфатированного АГ исследованы методом АСМ. В отличие от РЭМ метод АСМ позволяет измерять не только латеральные размеры нанонобъектов, но и их высоту с высокой точностью, вплоть до 0,1 нм [9].

Согласно данным АСM (рис. 4а, г), поверхность пленки сульфатированного АГ сформирована достаточно однородными частицами сферической формы со средним диаметром 70 нм. Величина среднеквадратичной шероховатости, рассчитанная по профилю поперечного сечения поверхности (рис. 4в), равна 33 нм.

Согласно изображениям фазового контраста (рис. 4б), поверхность пленки сульфатированного АГ достаточно однородна и не содержит посторонних примесей.

Рис. 1. КР-спектры

образцов: исходного (1)

и сульфатированного АГ (2)
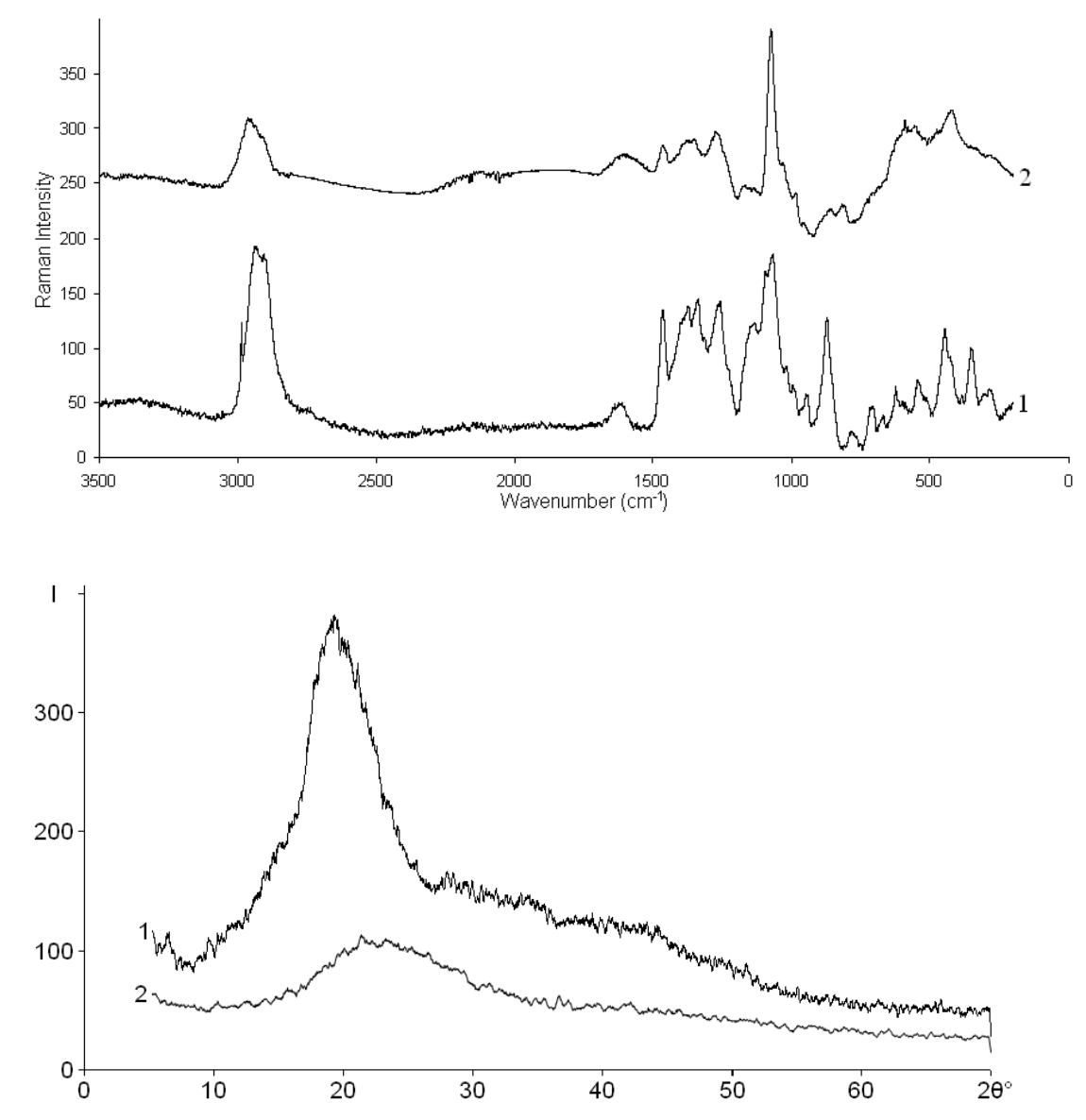

Рис. 2. Рентгенограммы образцов: исходного (1) и сульфатированного $\mathrm{A \Gamma}(2)$ 
$a$

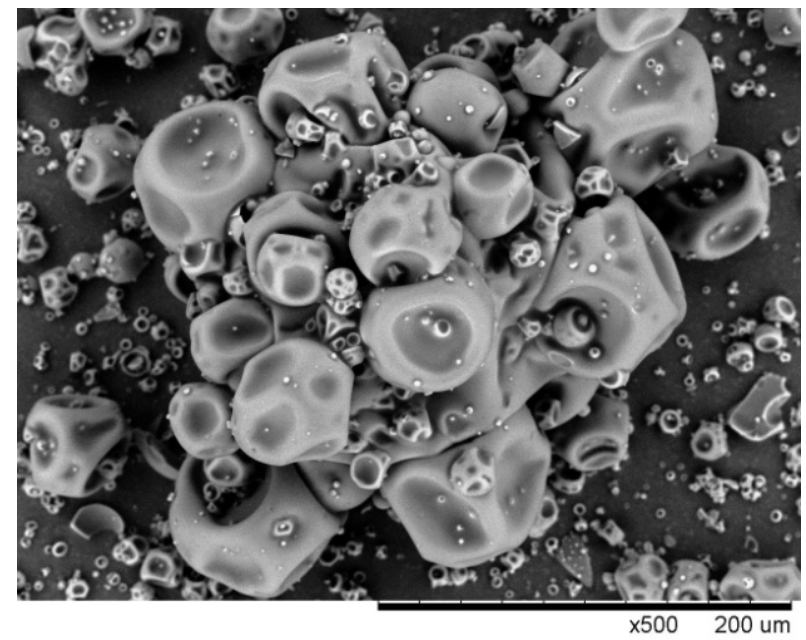

6

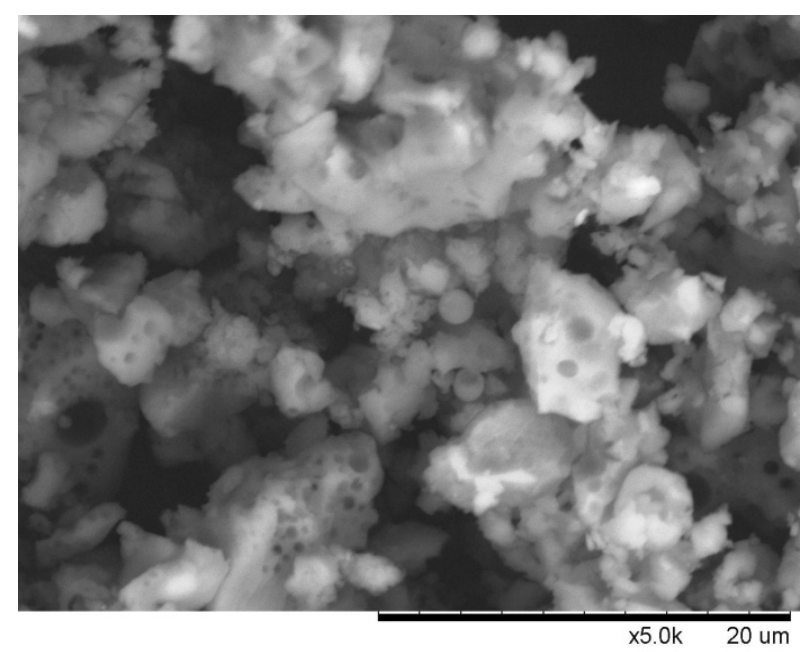

Рис. 3. РЭМ изображения образцов: исходного (a) и сульфатированного (б) АГ

$a$

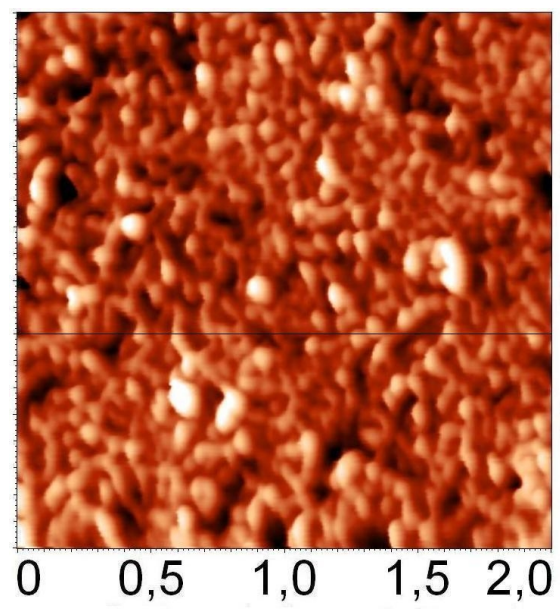

B

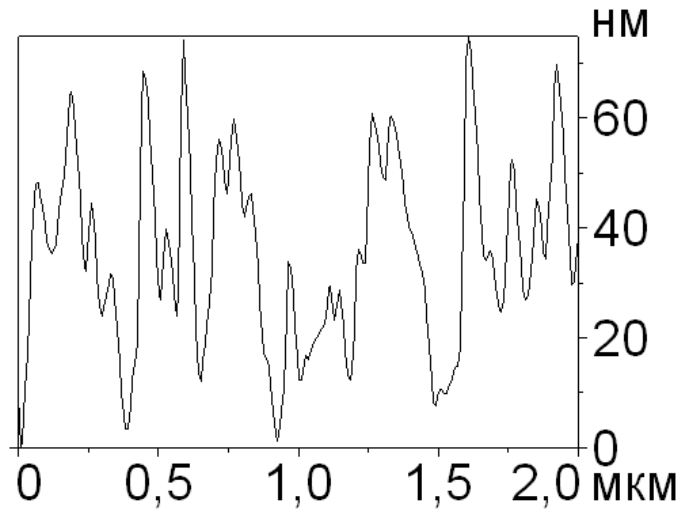

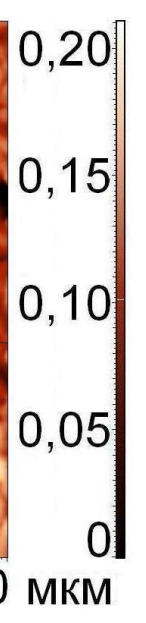

6

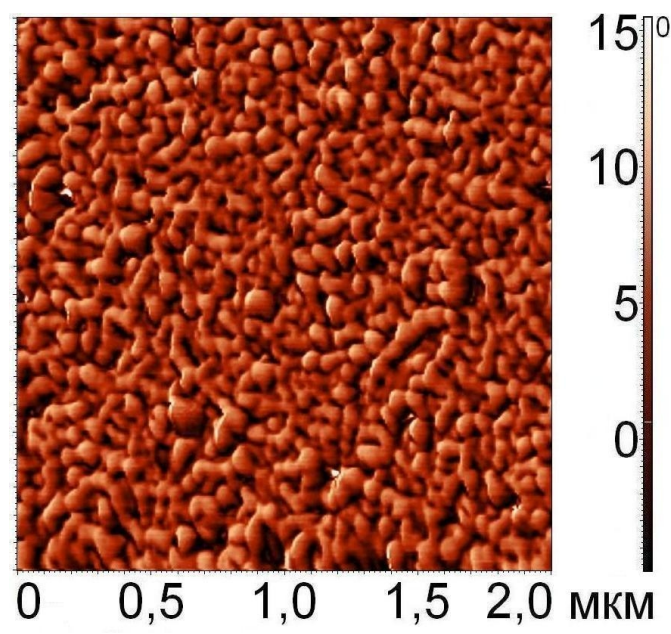

2 


\section{Заключение}

Методами КР, РФА, РЭМ и АСМ изучены сульфаты арабиногалактана, полученные новым способом - сульфатированием АГ из древесины лиственницы сульфаминовой кислотой в диоксане в присутствии мочевины. Введение сульфатных групп в структуру полисахарида подтверждено появлением в КРспектрах новых полос поглощения, характерных для колебаний связей сульфатной группы.

Показано, что при сульфатировании АГ происходит изменение его морфологии и дальнейшая аморфизация структуры. В отличие от исходного АГ, преимущественно состоящего из сферических частиц размером от 10 до 90 мкм, сульфатированный АГ сформирован частицами различной формы с размерами 1-8 мкм.

Согласно данным АСМ, поверхность пленки сульфатированного АГ образована достаточно однородными кристаллитами сферической формы со средним диаметром 70 нм и не содержит посторонних примесей.

\section{Список литературь}

1. Desai U.R. New antithrombin-based anticoagulants // Medicinal Research Reviews. 2004. Vol. 24, N2. Pp. 151-181.

2. Alban S., Schauerte A., Franz G. Anticoagulant sulfated polysaccharides: Part I. Synthesis and structure-activity relationships of new pullulan sulfates // Carbohydrate Polymers. 2002. Vol. 47, N3. Pp. 267-276.

3. Костыро Я.А., Медведева С.А., Сухов Б.Г. Синтез сульфатированных производных арабиногалактана // Техника машиностроения. 2004. №3. С. 10-12.

4. Патент №101054420 (Китай). Preparation of arabinogalactan sulfate from arabinogalactan / Guizhen Fang, Yanli Мa. 17.10.2007.

5. Васильева Н.Ю., Левданский А.В., Казаченко А.С., Дьякович Л., Пинель К., Кузнецов Б.Н. Сульфатирование механоактивированного арабиногалактана комплексом серный ангидрид - пиридин в среде пиридина // Журнал Сибирского федерального университета. Химия. 2013. Т. 6, №2. С. 158-169.

6. Васильева Н.Ю., Левданский А.В., Кузнецов Б.Н., Скворцова Г.П., Казаченко А.С., Дьякович Л., Пинель К. Сульфатирование арабиногалактана сульфаминовой кислотой в диоксане // Химия растительного сырья. 2014. №1. C. 87-95.

7. Zhang K., Brendler E., Fischer S. FT Raman investigation of sodium cellulose sulfate // Cellulose. 2010. Vol. 17, N2. Pp. 427-435.

8. Сухов Б.Г., Александрова Г.П., Грищенко Л.А., Феоктистова Л.П., Сапожников А.Н., Пройдакова О.А., Тьков А.В., Медведева С.А., Трофимов Б.А. Нанобиокомпозиты благородных металлов на основе арабиногалактана: получение и строение // Журнал структурной химии. 2007. Т. 48, №5. С. 979-984.

9. Bhushan B., Fuchs H., Hosaka S. Applied Scanning Probe Methods I. New York: Springer-Verlag Berlin Heidelberg, 2004. $476 \mathrm{p}$.

Поступило в редакиию 18 ноября 2016 г.

После переработки 21 ноября 2016 г. 
Kuznetsov B.N. ${ }^{1,2 *}$, Vasilyeva N.Yu. ${ }^{1,2}$, Levdansky A.V. ${ }^{l}$, Karacharov A.A. ${ }^{1}$, Krylov A.S. ${ }^{3}$, Mazurova E.V. ${ }^{l}$, Bondarenko G.N. ${ }^{l}$, Levdansky V.A. ${ }^{1,2}$, Kazachenko A.S. ${ }^{1,2}$ STUDY BY RAMAN SPECTROSCOPY, XRD, SEM, AFM METHODS THE SULFATES OF ARABINOGALACTAN OBTAINED WITH THE USE OF SULFAMIC ACID

${ }^{I}$ Institute of Chemistry and Chemical Technology SB RAS, FRC KSC SB RAS, Akademgorodok, 50-24, Krasnoyarsk 660036 (Russia),e-mail: inm@icct.ru

${ }^{2}$ Siberian Federal University, pr. Svobodny, 79, Krasnoyarsk, 660041 (Russia)

${ }^{3}$ Kirensky Institute of Physics SB RAS, FRC KSC SB RAS, Akademgorodok, 50-38, Krasnoyarsk, 660036 (Russia)

The structure of sodium salts of sulfated arabinogalactan (AG), obtained by sulfation of larch wood AG with sulfamic acid - urea mixture in the medium of 1,4-dioxane was investigated with the use of Raman spectroscopy, X-ray diffraction (XRD), scaning electron microscopy (SEM) and aromatic force microscopy (AFM) methods. The introduction of sulfate groups into the structure of AG was confirmed by appearance in Raman spectra new absorption bands characteristic for the deformation vibrations of $\delta\left(\mathrm{SO}_{3}\right)$ at $420 \mathrm{~cm}^{-1}$ and $\delta(\mathrm{O}=\mathrm{S}=\mathrm{O})$ at $588 \mathrm{~cm}^{-1}$, stretching vibrations $v(\mathrm{C}-\mathrm{O}-\mathrm{S})$ at $822 \mathrm{~cm}^{-1}$, symmetric stretching vibrations $v_{\mathrm{s}}(\mathrm{O}=\mathrm{S}=\mathrm{O})$ at $1076 \mathrm{~cm}^{-1}$, asymmetric stretching vibrations $v_{\text {as }}(\mathrm{O}=\mathrm{S}=\mathrm{O})$ at $1269 \mathrm{~cm}^{-1}$. According to XRD data the amorphization of arabinogalactan structure take place during it's sulfation. The difference in the morphology of initial and sulfated arabinogalactans was established by SEM method. Initial arabinigalactan consists of particles of globular shape with size of 10-90 $\mu \mathrm{m}$, but sulfates of AG - from particles of different shapes and sizes of 1-8 $\mu \mathrm{m}$. According to AFM data the surface of film of arabinogalactan sulfates is formed by the rather homogeneous spherical particles with sizes near $70 \mathrm{~nm}$. The mean-square value of the surface rounghness is equal to $33 \mathrm{~nm}$.

Keywords: physicochemical investigation, sulfated arabinogalactan, "green" synthesis, sulfamic acid, urea.

\section{References}

1. Desai U.R. Medicinal Research Reviews, 2004, vol. 24, no. 2, pp. 151-181.

2. Alban S., Schauerte A., Franz G. Carbohydrate Polymers, 2002, vol. 47, no. 3, pp. 267-276.

3. Kostyro Ia.A., Medvedeva S.A., Sukhov B.G. Tekhnika mashinostroeniia, 2004, no. 3, pp. 10-12. (in Russ.).

4. Patent 101054420 (China). 17.10.2007.

5. Vasil'eva N.Iu., Levdanskii A.V., Kazachenko A.S., D'iakovich L., Pinel' K., Kuznetsov B.N. Zhurnal Sibirskogo federal'nogo universiteta. Khimiia, 2013, vol. 6, no. 2, pp. 158-169. (in Russ.).

6. Vasil'eva N.Iu., Levdanskii A.V., Kuznetsov B.N., Skvortsova G.P., Kazachenko A.S., D'iakovich L., Pinel' K. Khimiia rastitel'nogo syr'ia, 2014, no. 1, pp. 87-95. (in Russ.).

7. Zhang K., Brendler E., Fischer S. Cellulose, 2010, vol. 17, no. 2, pp. 427-435.

8. Sukhov B.G., Aleksandrova G.P., Grishchenko L.A. Feoktistova L.P., Sapozhnikov A.N., Proidakova O.A., T'kov A.V., Medvedeva S.A., Trofimov B.A. Zhurnal strukturnoi khimii, 2007, vol. 48, no. 5, pp. 979-984. (in Russ.).

9. Bhushan B., Fuchs H., Hosaka S. Applied Scanning Probe Methods I. New York: Springer-Verlag Berlin Heidelberg, 2004. 476 p.

Received November18, 2016

Revised November 21, 2016

\footnotetext{
* Corresponding author.
} 